\section{Original Article}

\section{Check for updates}

\section{OPEN ACCESS}

Received: May 21, 2018

Revised: Oct 20, 2018

Accepted: Oct 29, 2018

Correspondence to

Chang-Keun Kim, MD, PhD

Asthma and Allergy Center, Department

of Pediatrics, Inje University Sanggye Paik

Hospital, 1342 Dongil-ro, Nowon-gu,

Seoul 01757, Korea.

Tel: +82-2-950-8832

Fax: +82-2-950-1662

E-mail:kimck@paik.ac.kr

Copyright (c) 2019 The Korean Academy of Asthma, Allergy and Clinical Immunology .

The Korean Academy of Pediatric Allergy and

Respiratory Disease

This is an Open Access article distributed under the terms of the Creative Commons Attribution Non-Commercial License (https:// creativecommons.org/licenses/by-nc/4.0/) which permits unrestricted non-commercial use, distribution, and reproduction in any medium, provided the original work is properly cited.

ORCID iDs

Chang-Keun Kim (D)

https://orcid.org/0000-0003-4119-2849 Zak Callaway (iD)

https://orcid.org/0000-0002-1812-9772

Hyo-Bin Kim iD

https://orcid.org/0000-0002-1928-722X Yoon-Seok Chang iD

https://orcid.org/0000-0003-3157-0447 Soo-Jong Hong (iD

https://orcid.org/0000-0003-1409-2113 Jae-Won Oh (iD

https://orcid.org/0000-0003-2714-0065

Hyun Hee Kim iD

https://orcid.org/0000-0002-4905-9391

\title{
Multicenter Adherence Study of Asthma Medication for Children in Korea
}

\author{
Chang-Keun Kim (1), ${ }^{1 *}$ Zak Callaway $\mathbb{1}$, ${ }^{1,2}$ Jungi Choi,' Hyo-Bin Kim $\left(\mathbb{D},{ }^{1}\right.$ Eun Mi Kwon, \\ Yoon-Seok Chang $\left(\mathbb{1},{ }^{3}\right.$ Yeong-Ho Rha, ${ }^{4}$ Soo-Jong Hong $\left(10,{ }^{5}\right.$ Jae-Won Oh $(1),{ }^{6}$ \\ Hyun Hee Kim (10,7 Dae Hyun Lim (1), ${ }^{8}$ Sung Won Kim, ${ }^{9}$ Kang Seo Park (iD, ${ }^{10}$ \\ Yong Hoon Cho, ${ }^{11}$ Hai Lee Chung $\left(\mathbb{1},{ }^{12}\right.$ Hee Ju Park, ${ }^{13}$ Sang-Gun Jung, ${ }^{14}$ Im Joo Kang, ${ }^{15}$ \\ Myung Chul Hyun, ${ }^{16}$ Moo-Young Oh, ${ }^{17}$ Jin A Jung, ${ }^{18}$ Myung Sung Kim, ${ }^{19}$ \\ Jung Yeon Shim (i), ${ }^{20}$ Jin Tack Kim, ${ }^{21}$ Young Yull Koh, ${ }^{22}$ and KAPARD Work Group on \\ Asthma Medication Compliance
}

'Asthma and Allergy Center, Department of Pediatrics, Inje University Sanggye Paik Hospital, Seoul, Korea ${ }^{2}$ School of Biological Sciences, College of Natural Science, University of Ulsan, Ulsan, Korea

${ }^{3}$ Department of Internal Medicine, Seoul National University Bundang Hospital, Seoul National University College of Medicine, Seongnam, Korea

${ }^{4}$ Department of Pediatrics, School of Medicine, Kyung Hee University, Seoul, Korea

${ }^{5}$ Department of Pediatrics, Childhood Asthma and Atopy Center, Asan Medical Center, Seoul, Korea

${ }^{6}$ Department of Pediatrics, Hanyang University College of Medicine, Seoul, Korea

${ }^{7}$ Department of Pediatrics, The Catholic University of Korea Uijeongbu St. Mary's Hospital, Uijeongbu, Korea

${ }^{8}$ Department of Pediatrics, Inha University Hospital, Incheon, Korea

${ }^{9}$ Department of Pediatrics, Busan St. Mary Hospital, Busan, Korea

${ }^{10}$ Department of Pediatrics, Presbyterian Medical Center, Jeonju, Korea

"Rose Mary's Hospital, Daegu, Korea

${ }^{12}$ Department of Pediatrics, Daegu Catholic University Medical Center, Catholic University of Daegu, Daegu, Korea

${ }^{13}$ Department of Pediatrics, College of Medicine, Pusan National University, Busan, Korea

${ }^{14}$ Department of Pediatrics, Good Kang-An Hospital, Busan, Korea

${ }^{15}$ Department of Pediatrics, FATIMA Hospital, Daegu, Korea

${ }^{16}$ Department of Pediatrics, School of Medicine, Kyungpook National University, Daegu, Korea

${ }^{17}$ Department of Pediatrics, Inje University Busan Paik Hospital, Busan, Korea

${ }^{18}$ Department of Pediatrics, Dong-A University College of Medicine, Busan, Korea

${ }^{19}$ Department of Pediatrics, I Dream Place Children's Hospital, Daegu, Korea

${ }^{20}$ Department of Pediatrics, Kangbuk Samsung Hospital, Sungkyunkwan University School of Medicine, Seoul, Korea

${ }^{21}$ Department of Pediatrics, The Catholic University of Korea Uijeongbu St. Mary's Hospital, Uijeongbu, Korea

${ }^{22}$ Department of Pediatrics, College of Medicine, Seoul National University, Seoul, Korea

\section{ABSTRACT}

Purpose: Adherence is a major component of successful medical treatment. However, nonadherence remains a barrier to effective delivery of healthcare worldwide.

Methods: Twenty healthcare facilities (secondary or tertiary hospitals) belonging to the Korean Academy of Pediatric Allergy and Respiratory Diseases (KAPARD) participated. Questionnaires were given to patients currently receiving treatment in the form of inhalant useor oral intake or transdermal patch for mild to moderate asthma.

Results: A total of 1,838 patients responded to the questionnaire. Mean age was $5.98 \pm 3.79$ years (range: $0-18$ years). With help from their caregivers, the percentage of patients that answered "taking as prescribed" was 38.04\% for inhalant users, 50.09\% for oral medication users and $67.42 \%$ for transdermal users. Transdermal patch users had significantly greater adherence compared to the other 2 groups $(P<0.001)$. The $34.15 \%$ of inhalant users, $70.33 \%$ of oral medication users and $93.00 \%$ of transdermal patch users felt that their medication 
Dae Hyun Lim (D)

https://orcid.org/0000-0002-4558-3284 Kang Seo Park (D)

https://orcid.org/0000-0003-3983-9770

Hai Lee Chung (iD)

https://orcid.org/0000-0002-5364-5318

Jung Yeon Shim (D)

https://orcid.org/0000-0001-9367-2233

Disclosure

There are no financial or other issues that

might lead to conflict of interest. delivery system was "Easy" or "Very easy" to use $(P<0.001)$. "Method of administration" was deemed to be the most difficult part of the treatment regimen to follow, and $76.7 \%$ of patients preferred once-daily administration (i.e., "Frequency of administration"). Conclusions: Asthma medication adherence in young children was found to be better in the transdermal patch group. This may be due to requiring fewer doses and easy to follow instructions. From an adherence point of view, the transdermal patch seems more useful for long-term asthma control in children compared to oral or inhaled medicine.

Keywords: Adherence; asthma; medication

\section{INTRODUCTION}

Adherence, or compliance, is an essential aspect of effective healthcare delivery. However, non-adherence is a worldwide problem. Adherence in long-term therapy for chronic illnesses in developed countries is estimated at $50 \%$, while the rate is even lower in developing countries. ${ }^{1}$ Adherence is important for a number of reasons, including improved healthcare outcomes, decreased healthcare costs and enhanced patient safety. It is also an important modifier of health system effectiveness. It has even been suggested that increasing the effectiveness of adherence interventions may have a much greater impact on population health than any improvement in specific medical treatments. ${ }^{2}$

Improving adherence in asthma therapy can be especially challenging for a number of reasons. In general, improvements in short-term treatment ( $<2$ weeks) adherence can often be achieved by giving clear instructions, while long-term therapeutic regimens require a combination of clear and detailed instructions, counseling on the importance of adherence and how to best organize daily dosages, reminders about appointments and adherence, a reward system for the patient's successful adherence (especially important in children), and the support of family and friends. ${ }^{3}$ More specifically, asthmatic patient and caregiver education and self-management have been shown to be tremendously beneficial, while noncomprehensive approaches to asthma management, such as providing information only, have not demonstrated improvements in health outcomes. ${ }^{4}$

This study was the first nationwide survey of young asthmatic patients and caregivers in Korea that aimed to investigate adherence in 3 common asthma therapy delivery systems (i.e., inhaled or oral corticosteroids or transdermal $\beta_{2}$-agonist) and identify possible reasons for nonadherence.

\section{MATERIALS AND METHODS}

\section{Participants}

Participants in this study were 2,000 asthmatic patients currently receiving treatment in the form of inhalant use or oral intake or transdermal patch for mild to moderate asthma. Twenty healthcare facilities (secondary or tertiary hospitals) belonging to the Korean Academy of Pediatric Allergy and Respiratory Diseases (KAPARD) participated. The participating hospitals were as follows: Catholic University of Korea Bucheon St. Mary's Hospital ( $\mathrm{n}=$ 100, 5.44\%); Kangbuk Samsung Hospital ( $n=100,5.44 \%)$; Kyongpook National University Hospital ( $n=105,5.71 \%)$; Kyunghee University Hospital $(n=103,5.6 \%)$; Daegu Catholic 
University Medical Center ( $n=98,5.33 \%)$; Dong-A University ( $n=101,5.5 \%)$; Rosemary's Hospital ( $n=1065.77 \%)$; Busan National University School of Medicine $(n=100,5.44 \%)$; Inje University Sanggye Paik Hospital A ( $\mathrm{n}=99,5.39 \%)$; Seoul National University Hospital ( $n=100,5.44)$; Asan Medical Center $(n=102,5.55 \%)$; Soon Chun Hyang University Hospital Cheonan ( $\mathrm{n}=99,5.39 \%)$; I Dream Place Children's Hospital $(n=55,2.99 \%)$; Catholic University of Korea Uijeongbu St. Mary's Hospital ( $\mathrm{n}=99,5.39 \%)$; Inje University Busan Paik Hospital ( $\mathrm{n}=54,2.94 \%)$; Inha University Hospital $(\mathrm{n}=30,1.63 \%)$; Presbyterian Medical Center ( $\mathrm{n}=33,1.8 \%)$; Good Gang-an Hospital $(\mathrm{n}=53,2.88 \%)$; and Hanyang University Medical Center $(\mathrm{n}=101,5.5 \%)$.

Because asthma is a heterogeneous disease and especially difficult to diagnose in this age group, the definition of asthma used was based on the GINA guidelines. The major inclusion criteria were: 1) 3 or more recurrent wheezing episodes within the last year, with at least 1 confirmed by a physician, and multiple-trigger wheeze (not just the common cold but other triggers, such as exercise, crying, laughing, etc.;) and 2) improvement of wheezing after administration of inhaled or oral short-acting $\beta_{2}$-agonists.

For severity, the GINA symptom classification based on daytime symptoms, nighttime symptoms and exertional symptoms was used. All patients were classified as having mild to moderate asthma.

\section{Administration and contents of the questionnaire}

This questionnaire-based study was carried out from March 2010 to February 2012. While visiting the clinic or hospital, asthmaic patients and their caregivers were given the questionnaire and they completed it on the spot or at home then mailed it in. The questions and answers are detailed in Table 1. Questions concerning sex, age, and underlying disease and severity were also included.

\section{Medication}

The tulobuterol patch (TP) is a transdermal patch containing the long-acting $\beta_{2}$-agonist (LABA), tulobuterol. It is designed to exert sustained $\beta_{2}$-agonist effects for 24 hours when applied once daily. The TP has been shown to improve lung function. ${ }^{5}$

Inhaled medication included: dry powder inhaler long-acting $\beta_{2}$-agonist (DPI-LABA); metered-dose inhaler short-acting $\beta_{2}$-agonist (MDI-SABA); DPI-inhaled corticosteroids (DPIICS); MDI-ICS; Budecort respules (aqueous solution of budesonide, an ICS); and Ventolin nebules (nebulized salbutamol, a SABA).

Oral medication included: leukotriene receptor antagonists (LTRAs), Montelukast and Pranlukast; oral corticosteroids (OCS); Theophylline; and Formoterol.

\section{Statistical analysis}

Using SPSS software, answers regarding adherence to treatment, convenience and willingness to replace drug formulation were analyzed using the Mann-Whitney $U$ test. Answers regarding reasons for poor adherence were analyzed using the $Z$-test for comparisons inhaled, oral, and transdermal drugs. Sex proportions were analyzed using the $\chi^{2}$ test, while age was analyzed using the Wilcoxon rank sum test. The level of statistical significance was set at $P<0.05$. 
Table 1. Questionnaire

\begin{tabular}{|c|c|c|}
\hline Question No. & Question & Answers \\
\hline 1 & $\begin{array}{l}\text { Are you currently taking medication prescribed for asthma treatment as } \\
\text { directed by your physician? }\end{array}$ & $\begin{array}{l}\text { 1. Always taken as prescribed } \\
\text { 2. Sometimes failed to take as prescribed } \\
\text { 3. Frequently failed to take as prescribed } \\
\text { 4. Always failed to take as prescribed }\end{array}$ \\
\hline 2 & $\begin{array}{l}\text { What is the most commonly prescribed medication during the } 6 \text {-month } \\
\text { study period? }\end{array}$ & $\begin{array}{l}\text { 1. Patch } \\
\text { 2. Inhaler } \\
\text { 3. Oral }\end{array}$ \\
\hline 3 & $\begin{array}{l}\text { Please rate the convenience of use of your asthma drugs using the following } \\
\text { rank scale. }\end{array}$ & $\begin{array}{l}\text { 1. Difficult } \\
\text { 2. Slightly difficult } \\
\text { 3. Easy } \\
\text { 4. Very easy }\end{array}$ \\
\hline 4 & Which part of the treatment regimen was difficult to follow? & $\begin{array}{l}\text { 1. Method of administration } \\
\text { 2. Frequency of administration } \\
\text { 3. Time } \\
\text { 4. Other }\end{array}$ \\
\hline 5 & $\begin{array}{l}\text { Please indicate the most preferable frequency of administration for your } \\
\text { asthma drugs. }\end{array}$ & $\begin{array}{l}\text { 1. Once daily } \\
\text { 2. Twice daily } \\
\text { 3. Three times daily }\end{array}$ \\
\hline 6 & Who usually administers the drugs to the patient? & $\begin{array}{l}\text { 1. Mother or father } \\
\text { 2. Grandmother or grandfather or relative } \\
\text { 3. Family helper } \\
\text { 4. Self-administered }\end{array}$ \\
\hline 7 & Would you switch from inhaled medication to transdermal patch? & $\begin{array}{l}\text { 1. Definitely yes } \\
\text { 2. Probably yes } \\
\text { 3. Do not know } \\
\text { 4. Probably no } \\
\text { 5. Definitely no }\end{array}$ \\
\hline 8 & Would you switch from transdermal patch to inhaled medication? & $\begin{array}{l}\text { 1. Definitely yes } \\
\text { 2. Probably yes } \\
\text { 3. Do not know } \\
\text { 4. Probably no } \\
\text { 5. Definitely no }\end{array}$ \\
\hline
\end{tabular}

\section{RESULTS}

\section{Demographics}

A total of 1,838 patients completed and returned the questionnaire. Six hundred ninetyseven females (mean age, $5.93 \pm 3.89$ years) and 1,124 males (mean age, $6.00 \pm 3.71$ years) responded at an overall mean age of $5.98 \pm 3.79$ years, while 17 responders did not answer the sex question. There was no significant difference in age between females and males (Wilcoxon rank sum test; $P=0.511$ ); however, there was a significant difference in sex proportion $\left(\chi^{2}\right.$ test; $\left.P<0.001\right)$.

The number of participants from each healthcare center and proportion of the total are listed in the Methods section. These amounts differed significantly $(P<0.001)$.

\section{Questionnaire}

Question 1 asked, "Are you currently taking medication prescribed for asthma treatment as directed by your physician?" Comparing the 3 types of medications in Table 2, 38.04\% of inhalant users, $50.09 \%$ of oral users and $67.42 \%$ of TP users answered, "Always taken as prescribed." These 3 proportions significantly differed $(P<0.001)$. Within each group, the proportions that answered, "Always taken...", "Sometimes failed to take...", "Frequently failed to take...", or "Always failed to take..." also significantly differed $\left(\chi^{2}\right.$ test; $\left.P<0.001\right)$ (Fig. 1). 
Table 2. Ease of medication use

\begin{tabular}{lcc}
\hline Pathway & Number (\%) & $<$ value \\
\hline Inhaler & $515(33)$ & $0.01^{*}$ \\
Difficult & $532(33)$ \\
Slightly difficult & $433(27)$ \\
Easy & $110(7)$ \\
Very easy & $1,590(100)$ & $<0.001^{\dagger}$ \\
Total & & \\
Oral & $55(3)$ \\
Difficult & $426(26)$ \\
Slightly difficult & $844(52)$ \\
Easy & $297(18)$ \\
Very easy & $1,622(100)$ \\
Total & \\
Patch & $43(3)$ \\
Difficult & $67(4)$ \\
Slightly difficult & $724(46)$ \\
Easy & $738(47)$ \\
Very easy & $1,572(100)$ \\
Total &
\end{tabular}

${ }^{*} \chi^{2}$ test; ${ }^{\dagger}$ Rao-Scott $\chi^{2}$ test.

Inhaler

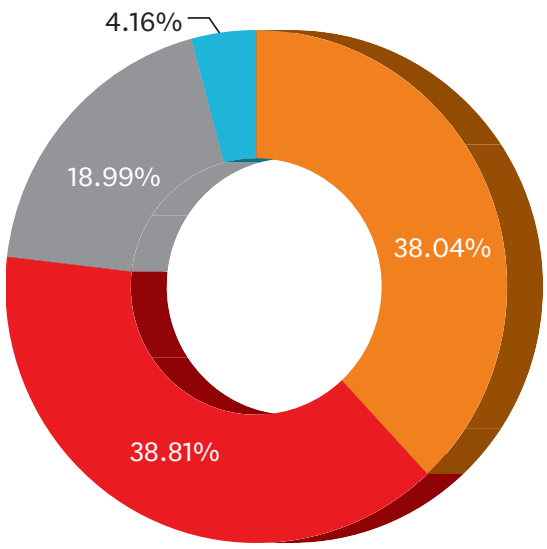

Oral

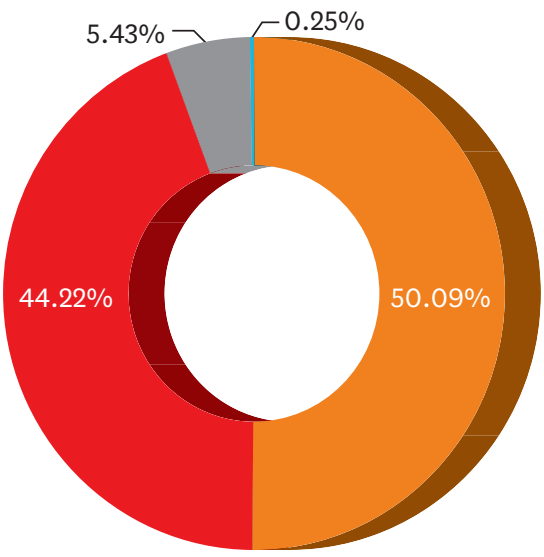

Patch

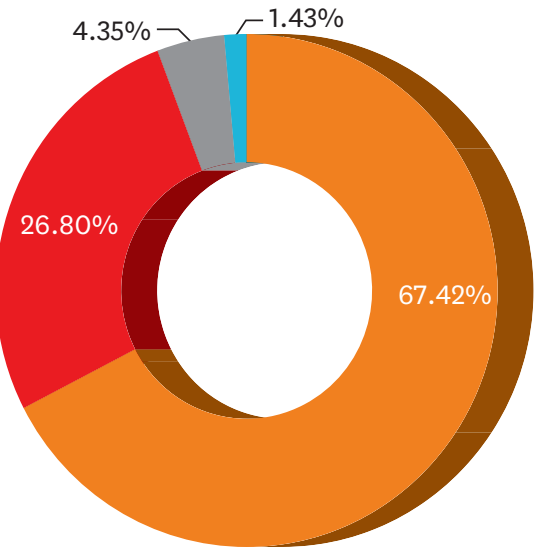

$P<0.001$

Always taken as prescribed

- Sometimes failed to take as prescribed - Frequently failed to take as prescribed

- Always failed to take as prescribed

Fig. 1. Adherence. Answers to Question 1, "Are you currently taking all asthma medications as prescribed?"

Question 2 asked, "What is the most commonly prescribed medication during the 6-month study period?" Referring to Fig. 2, 23.94\% $(\mathrm{n}=451)$ answered, "Patch", 32.27\% $(\mathrm{n}=608)$ answered "Inhaler" and $43.79 \%(\mathrm{n}=825)$ answered "Oral". The Rao-Scott $\chi^{2}$ test was performed and the above 3 proportions differed significantly $(P<0.001)$.

Question 3 asked "Please rate the convenience of use of your asthma drugs using the following rank scale." Referring to Table 2, 34.15\% of inhalant users, $70.33 \%$ of oral medication users and $93.00 \%$ of TP users felt that their medication delivery system was "Easy" or "Very easy" to use. These 3 proportions differed significantly $(P<0.001)$. Within each group, the proportions that answered "Difficult", "Slightly difficult", "Easy", or "Very easy" also differed significantly $(P<0.001)$. 


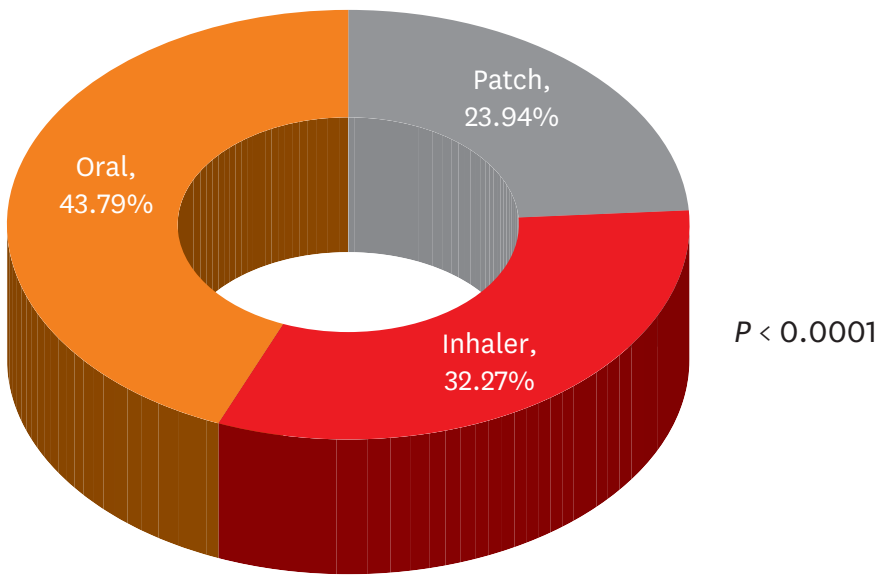

Fig. 2. The most common medication prescribed. Answers to Question 2, "What is the most commonly prescribed medication during the 6 -month study period?"

Question 4 asked "Which part of the treatment regimen was difficult to follow?" Of the 1,767 selected answers, 719 (40.80\%) were "Method of administration"; $510(28.86 \%)$ were "Frequency of administration"; 401 (22.69\%) were "Time"; and 135 (7.64\%) were "Others". There was a significant difference between the 4 answers $(P<0.001)$. Three respondents selected more than 1 answer and 74 of the 1,838 total patients enrolled in this study did not respond to the question.

Question 5 stated "Please indicate the most preferable frequency of administration for your asthma drugs." Of the 1,830 patients who responded to the question, 1,404 $(76.72 \%)$ selected "Once daily"; 379 (20.71\%) selected "Twice daily"; and 47 (2.57\%) selected "Three times daily". These 3 proportions differed significantly $(P<0.001)$. Eight patients did not respond to the question.

Question 6 asked "Who usually administers the drugs to the patient?" Of the total 1,825 responses to the question, 1,292 (70.6\%) were "Mother or Father"; 229 (12.51\%) chose "Grandmother or Grandfather or relative"; 28 (1.53\%) chose "Family helper"; and 281 $(15.36 \%)$ were "Self-administered". These 4 proportions differed significantly $(P<0.0001)$. Five respondents selected more than 1 answer and 13 of the total patients enrolled in this study did not respond to the question.

Question 7 asked "Would you switch from inhaled medication to transdermal patch?" Of the 1,656 patients who responded to this question, 493 (29.77\%) responded "Definitely yes"; 467 (28.20\%) responded "Probably yes"; 495 (29.89\%) responded "Do not know"; 114 (6.88\%) responded "Probably no"; and 87 (5.25\%) responded "Definitely no". These 5 proportions differed significantly $(P<0.0001)$. Of the total patients enrolled, 182 did not respond to the question (Fig. 3A).

Question 8 asked "Would you switch from transdermal patch to inhaled medication?" Of the 1,634 patients who responded to the question, 76 (4.65\%) chose "Definitely yes"; $117(7.16 \%)$ chose "Probably yes"; 577 (35.31\%) chose "Do not know"; 531 (32.50\%) chose "Probably no"; and $333(20.38 \%)$ chose "Definitely yes". These 5 proportions differed significantly $(P<$ 0.001) (Fig 3B). 
Inhalant users

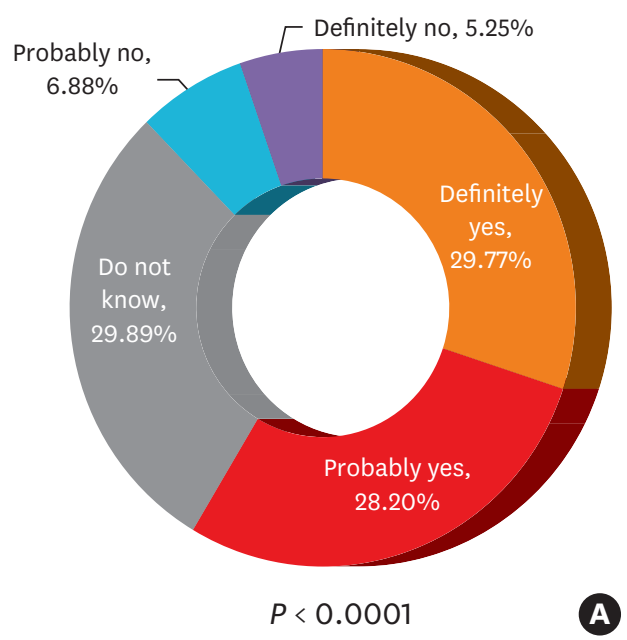

Patch users

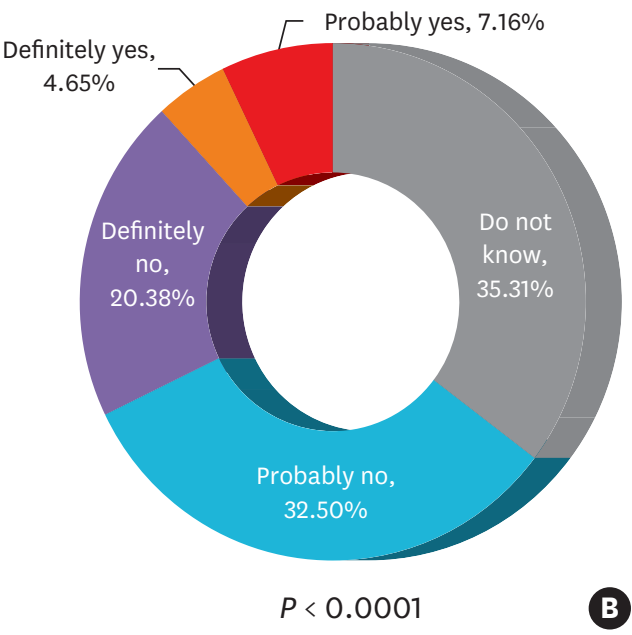

Fig. 3. Medication preference. (A) Inhalant users were asked, "Would you switch from inhaled medication to transdermal patch?" (Question 7). (B) Transdermal patch users were asked "Would you switch from transdermal patch to inhaled medication?" (Question 8).

\section{DISCUSSION}

Overall, the results obtained from this questionnaire-based survey of young children with mild to moderate asthma and their caregivers were expected. Due to the nature of the 3 different therapy delivery systems (i.e., inhalant use, oral intake and transdermal patch), adherence was highest in the TP group and significantly greater than in the other 2 groups. This result is congruent with those obtained by previous studies of asthma medication adherence. Tamura and Ohta ${ }^{6}$ found TP users to be significantly more likely to take their medication as prescribed than inhalant users ( $84 \%$ vs. 31.0\%-64.6\%). The reasons for higher adherence in our study may be elucidated by the other questions contained in our questionnaire. The ninety-three percent of our respondents found the TP to be convenient, which may be due to factors such as the frequency of administration (once per day) and the drug effect period (lasts for 24 hours). This led to nearly $60 \%$ of respondents stating they would switch from inhaled medications to TP.

Since its introduction in 1998, the TP-LABA has been used extensively in Korea, Japan and China; consequently, it has demonstrated clinical efficacy and safety. It is also associated with improvements in quality of life (QOL) for asthma and other chronic respiratory disease (e.g., chronic obstructive pulmonary disorder [COPD]). Beyond these attributes, however, are the benefits due to its specific formulation and delivery system for a bronchodilator. As the human body follows circadian rhythms, respiratory function is known to be most compromised from late night to early morning. ${ }^{8}$ Suppression of this "morning dip" in respiratory function would logically improve QOL, and in the case of childhood asthma also reduce burden on the caregiver(s). This particular TP maximizes blood drug concentration in the early morning and provides a sustained drug action for 24 hours. In a small study of pediatric patients with severe asthma and being treated with ICS, the once-daily TP exhibited an add-on effect equal to twice-daily doses of inhaled salmeterol, another LABA. ${ }^{9}$ 
Treatment adherence is a critical factor in the management of chronic disease and is especially true for asthma. There is documented worldwide poor adherence in asthma treatment $(30 \%-70 \%)$, with percentages being measured a number of ways: percentage of prescribed medication taken, serum theophylline levels, days of medication adherence or percentage of patients who failed to reach a clinically estimated adherence minimum. ${ }^{10}$ Adherence is also a serious consideration in vulnerable populations like children and adolescents, and has been measured as low as $30 \%$ in general practice. ${ }^{11}$ The importance of asthma treatment adherence cannot be overstated, as it not only has direct health consequences - for example, poor asthma control leading to exacerbation and decreased QOL - but also economic costs such as increased hospitalization and emergency department visits. ${ }^{1}$

One possible limitation of our study is the fact that caregivers often answered the questionnaire for young children. Measurement bias may have occurred because caregivers may have been reluctant to give socially unacceptable answers to questions regarding adherence. Another possible limitation may have been in the sex ratio (i.e., almost 2:1 for male:female. However, males tend to be afflicted by asthma more often than females.

Continued improvement in treatment adherence for chronic diseases such as asthma should be the focus of all practicing clinicians. Consistent administration of effective doses at the correct times is essential for asthma control, which is the goal of every healthcare personnel and caregiver dealing with this disease.

\section{REFERENCES}

1. World Health Organization. Adherence to long-term therapies: evidence for action. Geneva: World Health Organization; 2003.

2. Haynes RB, McDonald H, Garg AX, Montague P. Interventions for helping patients to follow prescriptions for medications. Cochrane Database Syst Rev 2002:CD000011. PUBMED | CROSSREF

3. Haynes RB, McDonald HP, Garg AX. Helping patients follow prescribed treatment: clinical applications. JAMA 2002;288:2880-3. PUBMED | CROSSREF

4. Gibson PG, Powell H, Coughlan J, Wilson AJ, Hensley MJ, Abramson M, et al. Limited (information only) patient education programs for adults with asthma. Cochrane Database Syst Rev 2002:CD001005. PUBMED | CROSSREF

5. Tamura G, Sano Y, Hirata K, Ishioka S, Nakashima M, Miyamoto T. Effect of transdermal tulobuterol added to inhaled corticosteroids in asthma patients. Allergol Int 2005;54:615-20. CROSSREF

6. Tamura G, Ohta K. Adherence to treatment by patients with asthma or COPD: comparison between inhaled drugs and transdermal patch. Respir Med 2007;101:1895-902. PUBMED | CROSSREF

7. Tamura G, Ichinose M, Fukuchi Y, Miyamoto T. Transdermal tulobuterol patch, a long-acting $\beta_{2}$-agonist. Allergol Int 2012;61:219-29. PUBMED | CROSSREF

8. Turner-Warwick M. On observing patterns of airflow obstruction in chronic asthma. Br J Dis Chest 1977;71:73-86. PUBMED | CROSSREF

9. Yoshihara S, Yamada Y, Abe T, Arisaka O. The use of patch formulation of tulobuterol, a long-acting $\beta_{2}$-adrenoreceptor agonist, in the treatment of severe pediatric asthma. Ann Allergy Asthma Immunol 2006;96:879-80.

PUBMED | CROSSREF 
10. Bender B, Milgrom H, Rand C. Nonadherence in asthmatic patients: is there a solution to the problem? Ann Allergy Asthma Immunol 1997;79:177-85.

PUBMED | CROSSREF

11. Dekker FW, Dieleman FE, Kaptein AA, Mulder JD. Compliance with pulmonary medication in general practice. Eur Respir J 1993;6:886-90.

PUBMED 